Check for updates

Cite this: Phys. Chem. Chem. Phys., 2020, 22, 16887

Received 29th April 2020 Accepted 9th July 2020

DOI: 10.1039/d0cp02307h

rsc.li/pccp

\title{
Structural characteristics of oligomers formed by pyroglutamate-modified amyloid $\beta$ peptides studied by solid-state NMR $\dagger$
}

\author{
Holger A. Scheidt, (D) *a Anirban Das, ${ }^{b}$ Alexander Korn, ${ }^{a}$ Martin Krueger, \\ Sudipta Maiti (D) ${ }^{b}$ and Daniel Huster (D) ab
}

\begin{abstract}
Neuronal plaques of amyloid $\beta$ (A $\beta$ ) peptides of varying length carrying different posttranslational modifications represent a molecular hallmark of Alzheimer's disease. It is believed that transient oligomeric $A \beta$ assemblies associating in early fibrillation events represent particularly cytotoxic peptide aggregates. Also, N-terminally truncated (in position 3 or 11) and pyroglutamate modified peptides exhibited an increased toxicity compared to the wildtype. In the current study, the molecular structure of oligomeric species of $p G l u_{3}-A \beta(3-40)$ and $p G l u_{11}-A \beta(11-40)$ was investigated using solid-state NMR spectroscopy. On the secondary structure level, for both modified peptides a large similarity between oligomers and mature fibrils of the modified peptides was found mainly based on ${ }^{13} \mathrm{C}$ NMR chemical shift data. Some smaller structural differences were detected in the vicinity of the respective modification site. Also, the crucial early folding molecular contact between residues $\mathrm{Ph}_{19}$ and $\mathrm{Leu}_{34}$ could be observed for the oligomers of both modified peptide species. Therefore, it has to be concluded that the major secondary structure elements of $A \beta$ are already present in oligomers of pGlu $-A \beta(3-40)$ and $p G u_{11}-A \beta(11-40)$. These posttranslationally modified peptides arrange in a similar fashion as observed for wild type $A \beta(1-40)$.
\end{abstract}

\section{Introduction}

In the development of Alzheimer's disease, especially the early aggregates in the fibrillation process of amyloid $\beta(\mathrm{A} \beta)$ peptides of varying length and posttranslational modifications are considered the most cytotoxic species, which initiate the development of the disease on the molecular level. ${ }^{1-5}$ While the molecular structure of the final mature fibrils of $A \beta$ has been very well studied, ${ }^{6-14}$ it still remains a significant challenge to catch these more disease-relevant intermediate oligomeric assemblies for structural investigations. Along with the application of special (and sometimes non-physiological) fibrillation conditions, ${ }^{15,16}$ spectral filtering in NMR measurements ${ }^{17}$ or the use of antibodies that specifically bind to folding intermediates, ${ }^{18,19}$ also freezedrying of oligomeric assemblies in liquid nitrogen ${ }^{20}$ has been used for such challenging endeavors. Most of these studies on oligomers suggest that the secondary structure elements - the two $\beta$-strands which are connected by a short loop - of $\mathrm{A} \beta$ are

\footnotetext{
${ }^{a}$ Institute for Medical Physics and Biophysics, Leipzig University Härtelstr. 16-18, D-04107 Leipzig, Germany. E-mail: holger.scheidt@medizin.uni-leipzig.de

${ }^{b}$ Department of Chemical Sciences, Tata Institute of Fundamental Research, Homi Bhabha Road, Colaba, Mumbai 400 005, India

${ }^{c}$ Institute of Anatomy, Leipzig University, Liebigstraße 13, 04103 Leipzig, Germany $\dagger$ Electronic supplementary information (ESI) available. See DOI: 10.1039/ d0cp02307h
}

formed very early in the fibrillation process ${ }^{16,18,20-22}$ even if the individual $\beta$-strands differ in their length. ${ }^{19}$ More differences between early species in the fibrillation process and mature fibrils were observed on the tertiary structure level: while in the mature fibrils the hydrogen bonds are intermolecular between the monomeric units leading to the formation of parallel $\beta$-sheets, in early $A \beta$ oligomers antiparallel $\beta$-sheets forming intramolecular hydrogen bonds were observed. ${ }^{18,22-25}$

It is now well described that during processing of the amyloid precursor protein by $\gamma$-secretase, amyloid peptides of varying lengths are released that exhibit altered cytotoxic potential. ${ }^{26}$ In addition, different posttranslational modifications as well as chemical reactions after processing further modify these $A \beta$ fragments. ${ }^{27-31}$ These different variants of the $\mathrm{A} \beta$ peptides also include $\mathrm{N}$-terminally truncated peptides, where the most N-terminal glutamate residue in position 3 or 11 is converted into a cyclic pyroglutamate. ${ }^{29,32}$ For both peptide species produced in this pathway $\left(\mathrm{pGlu}_{3}-\mathrm{A} \beta\right.$ and $\mathrm{pGlu}_{11}-\mathrm{A} \beta$ ) this posttranslational modification affects the fibrillation properties leading not only to increased oligomerization and fibrillation ${ }^{33-38}$ but also to higher cytotoxicity. ${ }^{34,39,40}$ Both modifications are abundant in the brain of $\mathrm{AD}$ and also Down syndrome patients $^{41,42}$ and were found in the core of senile plaques of Alzheimer's patients. ${ }^{37,43}$ Consequently, it is assumed that the pyroglutamate modified peptides play an essential role in the 
(early) development of $\mathrm{AD} .^{29,32,39}$ It has been shown in mice that the inhibition of the pGlu lactam ring producing enzyme reduced amyloid plaque deposition and retarded memory decline. ${ }^{35}$

Interestingly, the structural features of the mature fibrils formed by these pyroglutamate-modified peptides have been found to be very similar compared to WT-A $\beta .^{44,45}$ In fact, most modified and/or mutated $\mathrm{A} \beta$ peptides that exhibit a much altered cytotoxic characteristics ${ }^{46}$ show relatively mild structural alterations in the mature fibrillary state compared to the WT. ${ }^{47-50}$ Although the exact mechanism how oligomeric $A \beta$ peptides exert their toxic potential to neurons remains speculative, it is clear that the structural features of these aggregates must differ from those of mature fibrils. ${ }^{51}$ Here, we set out to characterize structural features of oligomers formed by $\mathrm{pGlu}_{3} \mathrm{~A} \beta(3-40)$ and $\mathrm{pGlu}_{11^{-}}$ $\mathrm{A} \beta(11-40)$ peptide oligomers using the freeze trapping method that has been introduced by Sarkar et $a .^{20}$

\section{Materials and methods}

\section{Oligomer preparation}

The differently isotope-labelled $\mathrm{A} \beta$ peptides were synthesized using standard Fmoc protocols. Uniformly ${ }^{13} \mathrm{C} /{ }^{15} \mathrm{~N}$-labeled amino acids were included as follows: pGlu $3-\mathrm{A} \beta(3-40)$ three differently labeled peptides: Peptide I: $\mathrm{Ser}_{8}, \mathrm{Val}_{12} \mathrm{Phe}_{19}, \mathrm{Leu}_{34}$; Peptide II: $\mathrm{Phe}_{4}, \mathrm{Glu}_{11}, \mathrm{Gly}_{29}, \mathrm{Val}_{36}$; and Peptide III: Asp ${ }_{7}, \mathrm{Gly}_{9}$, $\mathrm{Glu}_{22}, \quad \mathrm{Ile}_{31}$. For $\mathrm{pGlu}_{11}-\mathrm{A} \beta(11-40)$ four different labeled peptides: Peptide IV: Val $_{12} \mathrm{Phe}_{19}, \mathrm{Ala}_{21}, \mathrm{Leu}_{34} \mathrm{Gly}_{37}$; Peptide V: Leu $_{17}, \mathrm{Glu}_{22}, \mathrm{Gly}_{25}, \mathrm{Ile}_{31}$; Peptide VI: $\mathrm{Asp}_{23}, \mathrm{Lys}_{28}, \mathrm{Gly}_{33}, \mathrm{Val}_{39}$ and Peptide VII: pGlu $_{11}$, Gly Gl $_{29}$. For a graphical depiction of the labelling scheme, see also ESI, $\dagger$ Scheme S1. The labelling scheme was chosen to avoid spectral overlap in the NMR spectra. Labelled amino acids were concentrated close to the peptide modifications. Additionally, amino acids which are known to be involved in tertiary molecular contacts in other $\mathrm{A} \beta$ preparations were labelled in the same peptide (i.e., $\mathrm{Phe}_{19}-\mathrm{Leu}_{34}, \mathrm{Glu}_{22}-\mathrm{Ile}_{31}$ ).

The oligomer preparation followed the procedure described in the literature, ${ }^{20}$ where also a comprehensive biophysical characterization of these oligomers has been conducted. ${ }^{52,53}$ In brief, the peptides were dissolved as stock in 1 to $2 \mathrm{ml}$ ammonia solution at $\mathrm{pH} 11$ to start from a nearly monomeric state. This solution was diluted into $175 \mathrm{mM}$ ammonium acetate buffer ( $\mathrm{pH} 7.4$ ) to $25 \mu \mathrm{M} \mathrm{A} \beta$ solution. After $30 \mathrm{~min}$ of incubation, the oligomeric solution was flash-frozen by dropwise addition into liquid nitrogen and afterwards lyophilized to remove the water as well as the $\mathrm{NH}_{4} \mathrm{OAc}$. Finally, about 1.5 to $3.5 \mathrm{mg}$ of dry powder was obtained and transferred into $3.2 \mathrm{~mm}$ MAS rotors for NMR measurements.

\section{Fluorescence measurements for oligomer characterization}

Peptide stocks were prepared at $\mathrm{pH} 11$ in a similar way as mentioned above. They were stored at $-80{ }^{\circ} \mathrm{C}$ after flashfreezing in liquid nitrogen. Before starting the experiments, they were thawed quickly and used. For TPE-TPP (bis(triphenylphosphonium) tetraphenylethene), $1 \mathrm{mg}$ of the dye was dissolved in $1 \mathrm{~mL}$ of DMSO to prepare a stock solution of $1 \mathrm{mM}$.
The aggregation of each of the $A \beta$ peptides were started from an initial concentration of $25 \mu \mathrm{M}$ in $175 \mathrm{mM} \mathrm{NH}_{4} \mathrm{OAc}$ buffer (pH 7.5), incubated with $10 \mu \mathrm{M}$ TPE-TPP.

Fluorescence emission spectra of TPE-TPP were recorded at different time-points ( $t=0$ to 2 hours, at 30 minutes interval) using a quartz cuvette $(1 \mathrm{~cm} \times 1 \mathrm{~cm}$ path length $)$ on a FluoroMax-3 (Jobin Yvon, Horiba) spectrofluorimeter. TPE-TPP was excited at $330 \mathrm{~nm}$ and the emission was collected from 390 to $620 \mathrm{~nm}$. Excitation and emission slits both were kept at $5 \mathrm{~nm}$, and the integration time was fixed at $0.1 \mathrm{~s}$. Five consecutive spectra were recorded at each of the time-points and were averaged later on. Samples were thoroughly mixed before each scan.

\section{Electron microscopy}

The fibril morphology was evaluated and analyzed by electron microscopy (EM). Droplets of the prepared fibril solutions ( $1 \mu \mathrm{l}$ each) were placed on formvar- coated copper grids, allowed to dry for about $1 \mathrm{~h}$ and subsequently stained with $1 \%$ uranyl acetate in pure water. Electron microscopy was performed using a Zeiss SIGMA electron microscope, (Zeiss NTS, Oberkochen, Germany) equipped with a STEM detector and Atlas Software.

\section{Solid-state MAS NMR spectroscopy}

The MAS NMR experiments were conducted on a Bruker Avance III $600 \mathrm{MHz}$ or a Bruker Avance Neo $700 \mathrm{MHz}$ spectrometer (Bruker BioSpin GmbH, Rheinstetten, Germany) using triple channel $3.2 \mathrm{~mm}$ MAS probes. Typical pulse lengths were $4 \mu \mathrm{s}$ for ${ }^{1} \mathrm{H}$ and ${ }^{13} \mathrm{C}$ and $5 \mu$ s for ${ }^{15} \mathrm{~N} .{ }^{1} \mathrm{H}-{ }^{13} \mathrm{C}$ and ${ }^{1} \mathrm{H}-{ }^{15} \mathrm{~N}$ CP contact time were $1 \mathrm{~ms}$ at a spin lock field of $\sim 50 \mathrm{kHz}$. During acquisition, ${ }^{1} \mathrm{H}$ dipolar decoupling with a radio frequency field strength of $65 \mathrm{kHz}$ was applied using Spinal64. The MAS frequency was $11777 \mathrm{~Hz} .{ }^{13} \mathrm{C}$ chemical shifts were referenced externally relative to TMS. The relaxation delay in all experiments was $2.5 \mathrm{~s}$. All NMR experiments were carried out at a temperature of $30{ }^{\circ} \mathrm{C}$.

For all samples, ${ }^{13} \mathrm{C}-{ }^{13} \mathrm{C}$ DARR NMR spectra were acquired. If the ${ }^{15} \mathrm{~N}$ signal intensity allowed additional the detection ${ }^{15} \mathrm{~N}-{ }^{13} \mathrm{C} \alpha$ correlation spectra, they were acquired at the same time using dual-acquisition. ${ }^{54}$ In one experiment, a two dimensional ${ }^{13} \mathrm{C}-{ }^{13} \mathrm{C}$ DARR NMR spectrum with 128 data points and four identical ${ }^{15} \mathrm{~N}-{ }^{13} \mathrm{C} \alpha$ correlation spectra with 32 data points in the indirect dimensions were measured. The DARR mixing time was $500 \mathrm{~ms}$, in some cases, additional DARR spectra with a mixing time of $50 \mathrm{~ms}$ were acquired to exclude cross peaks from long range interactions.

\section{Results and discussion}

A very comprehensive characterizations of the biophysical properties of early $A \beta$ oligomers prepared by the procedure of Sarkar et $a l^{20}$ or very similar protocols can be found in the literature. ${ }^{52,53}$ In addition, we checked the morphology of the oligomer preparations by recording electron micrographs of the respective samples (Fig. 1). For both pyroglutamated 

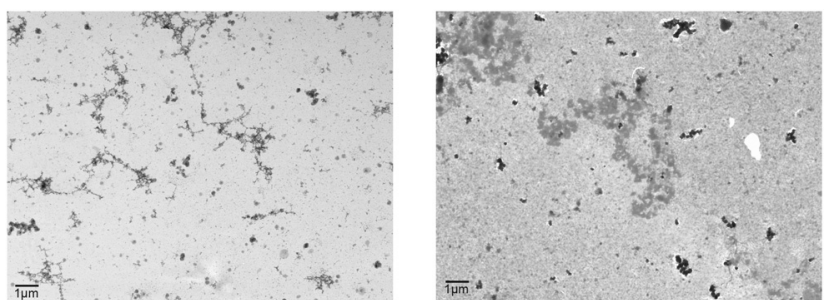

Fig. 1 Scanning transmission electron micrograph of the oligomer preparation of pGlu $-A \beta(3-40)$ (left) and pGlu p $_{11}-A \beta(11-40)$ (right). The scale bar represents $1.0 \mu \mathrm{m}$.

peptides, no fibrillar structures were observable. Instead a number of small spherical aggregates of varying size which sometimes cluster together are visible. Comparable structures were observed in the electron micrographs of different oligomer preparations. ${ }^{16,17,22,24,25,34,52,55}$

For further characterization of these oligomers, we investigated the state of aggregation of the modified $A \beta$ peptide by monitoring the fluorescence emission of the dye bis(triphenylphosphonium) tetraphenylethene (TPE-TPP), which shows a clear spectral change with maturation of the WT A $\beta(1-40)$ fibrils, and it can identify even the early small oligomeric species. $^{52}$ In the comparison of WT and both modified A $\beta$ peptides it is expected that if the similar spectral characteristics report similar structural characteristics.

Fig. S1 (ESI $\dagger$ ) shows the fluorescence emission of TPE-TPP as a function of time incubated with WT-A $\beta(1-40)$. A control solution (10 $\mu \mathrm{M}$ TPE-TPP in $175 \mathrm{mM} \mathrm{NH}_{4} \mathrm{OAc}$ buffer) containing only TPE-TPP at the same concentration showed very low or negligible intensity (data not shown), as observed previously. ${ }^{52}$ The observed emission maximum at $462 \mathrm{~nm}$ (till 1 to 1.5 hours), show that the solution contains mostly the small oligomeric aggregates $(n<10) .{ }^{52}$ For pGlu $3-\mathrm{A} \beta(3-40)$ and $\mathrm{pGlu}_{11}-\mathrm{A} \beta(11-40)$ very similar emission maxima of $461 \mathrm{~nm}$ (till about 1.5 hours) and $463 \mathrm{~nm}$ (till about 1 hour of incubation) are observed (Fig. 2). We would like to note here that the solution conditions in the current experiment ( $175 \mathrm{mM} \mathrm{NH}_{4} \mathrm{OAC} \mathrm{pH}$ ), is different from that used earlier ( $20 \mathrm{mM}$ phosphate and $150 \mathrm{mM} \mathrm{NaCl}) .^{52}$ However, the emission spectra for the WT-A $\beta_{40}$ appear to be very similar in both the buffers, so the results should be comparable. We therefore conclude that the species present after 30 minutes
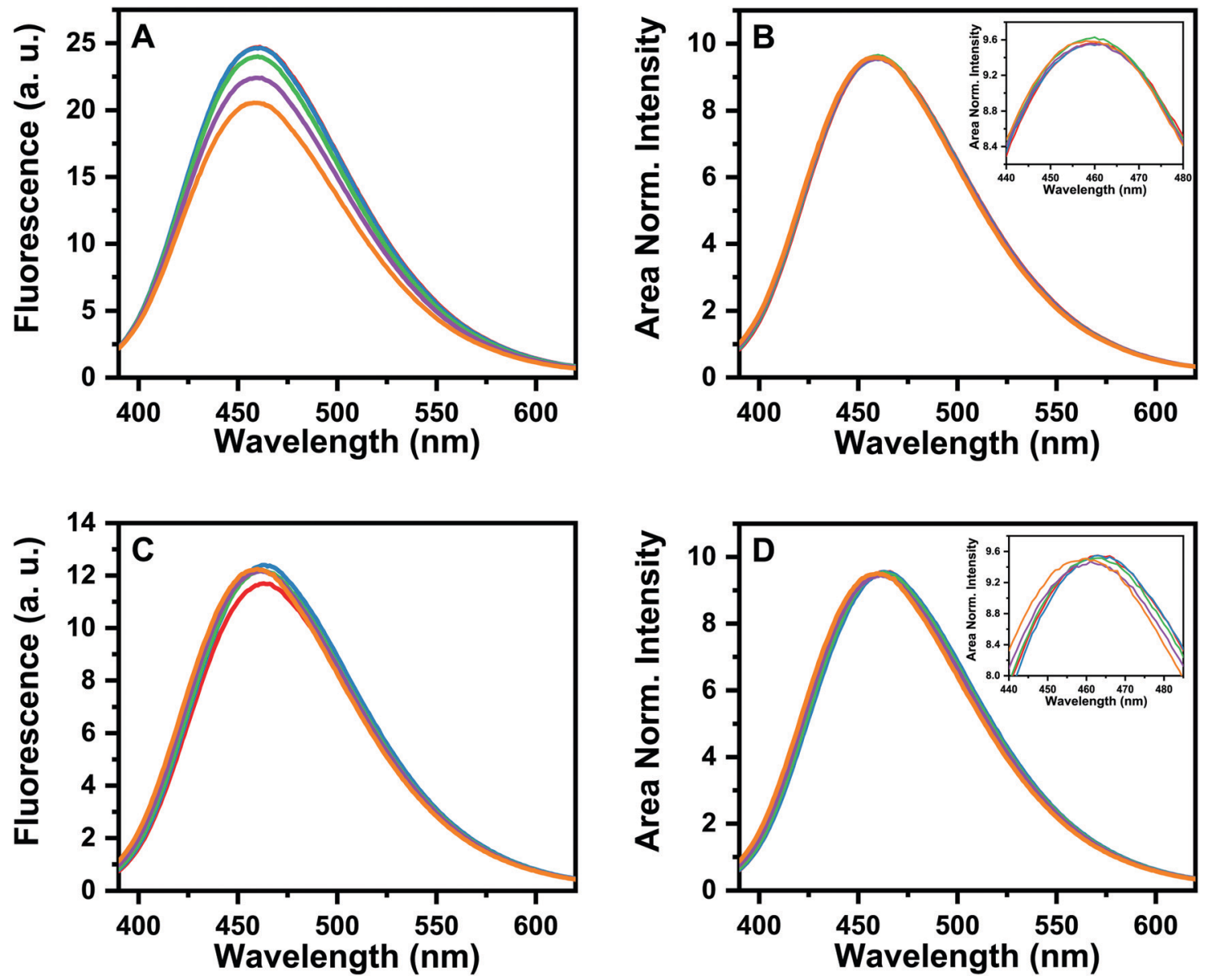

Fig. 2 Fluorescence emission of TPE-TPP as a function of time, when incubated with (A) $p G l u_{3}-A \beta(3-40)$ and (C) $p G l u_{11}-A \beta(11-40)$. Emission spectra were recorded at 5 different time points, at an interval of $30 \mathrm{~min}$ [ $t=0$ (red), $30 \mathrm{~min}$ (blue), $1 \mathrm{~h} \mathrm{(green),} 1.5 \mathrm{~h}$ (purple) and 2 hours (orange)]. $(B$ and $D)$ Same data as in panel $A$ and $C$ respectively, but area normalized. The respective insets show the magnified views of the peak regions of the spectra presented in (B and D). 
of incubation (as used in NMR experiments) in both pGlu ${ }_{3}^{-}$ $\mathrm{A} \beta(3-40)$ and $\mathrm{pGlu}_{11}-\mathrm{A} \beta(11-40)$ solutions are almost exclusively the small oligomers.

For more atomistic insights into the secondary structure of the respective peptides in the oligomeric aggregates, solid-stateNMR measurements were performed. The ${ }^{13} \mathrm{C} /{ }^{15} \mathrm{~N}$-labeled amino acids were concentrated in the regions close to the pyroglutamyl modification site of the respective peptide. For the oligomers of both modified peptides, the $1 \mathrm{D}^{13} \mathrm{C}$ CP MAS NMR spectra exhibit an increased line width compared to the spectra of the respective mature fibrils (see ESI, $\uparrow$ Fig. S2 and S3). This is probably caused by structural polymorphism in the samples, which is known for
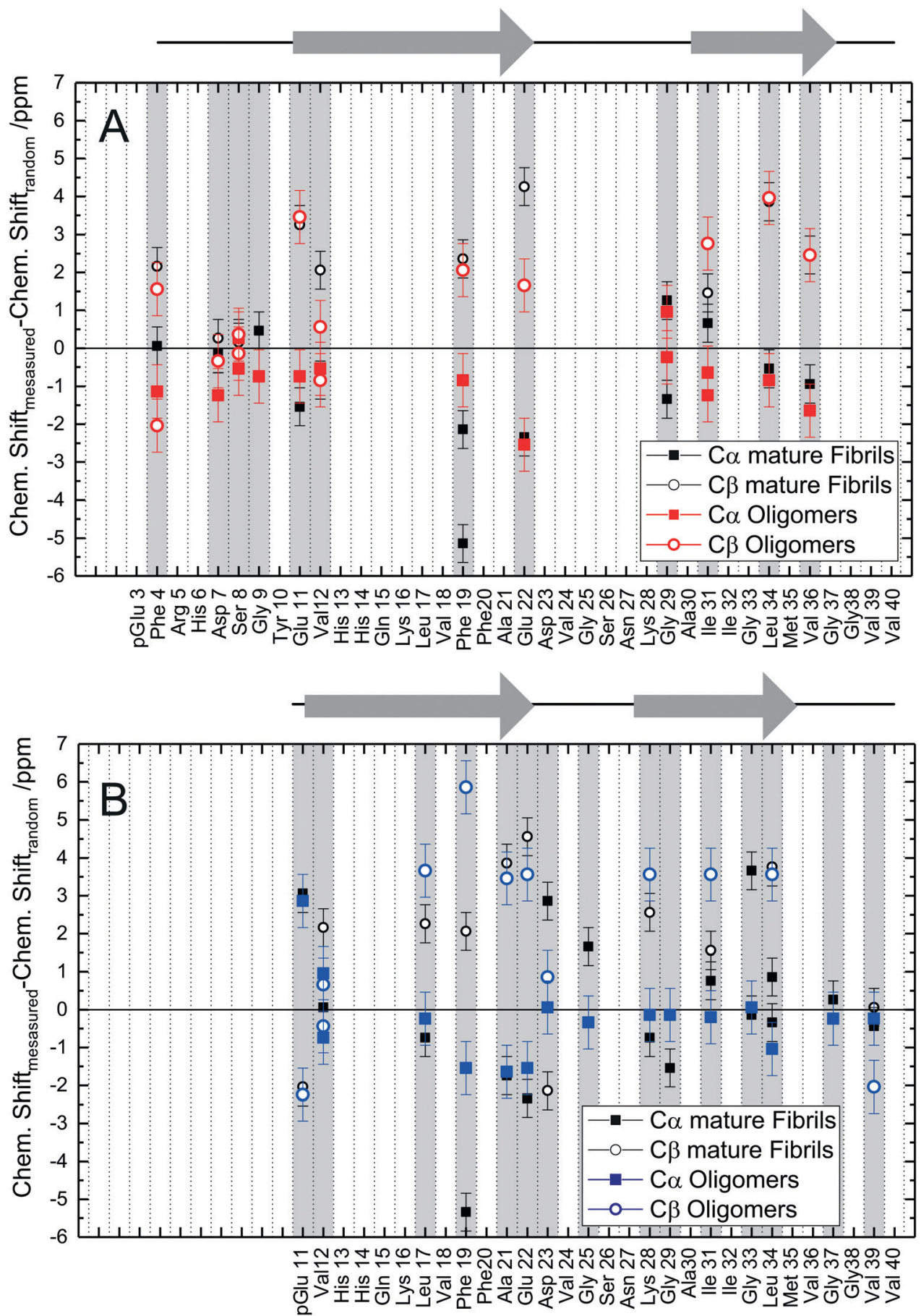

Fig. 3 Comparison of the secondary ${ }^{13} \mathrm{C}$ MAS NMR chemical shifts of the oligomers and the respective mature fibrils of $(A) p G l u_{3}-A \beta(3-40)$ and $(B)$ pGlu ${ }_{11}-A \beta(11-40)$ for ${ }^{13} \mathrm{C} \alpha$ (squares) and ${ }^{13} \mathrm{C} \beta$ (circles). Data are plotted as the difference of a measured chemical shifts to random coil chemical shifts taken from the literature. ${ }^{58}$ For the pGlu residues the random coil values of Glu were used as no reference values for pGlu are available. The values for the mature fibrils were taken from ref. 44 or 45 respectively. The arrows above the plots indicate $\beta$-strand secondary structure, the gray area in the plots highlight the ${ }^{13} \mathrm{C}$ labeled amino acids. 
WT-A $\beta$ peptides in different preparations ${ }^{6,19,20,56,57}$ but also a result of the current sample preparation since different oligomeric species will be present in the investigated samples.

For the assignment of the ${ }^{13} \mathrm{C}$ and in part also the ${ }^{15} \mathrm{~N}$ NMR signals, ${ }^{13} \mathrm{C}-{ }^{13} \mathrm{C}$ DARR (if necessary with short and long mixing times) and in cases where sufficient peptide quantities for good NMR sensitivity were achieved also ${ }^{15} \mathrm{~N}-{ }^{13} \mathrm{C} \alpha$ correlation spectra were acquired. Typical ${ }^{13} \mathrm{C}-{ }^{13} \mathrm{C}$ DARR spectra with a mixing time of $500 \mathrm{~ms}$ are shown in ESI, $\dagger$ Fig. S4. For some residues, more than one NMR signal was observed, which indicates structural polymorphism. The obtained chemical shift values are summarized in ESI, $\dagger$ Tables S1 and S2. Since the ${ }^{13} \mathrm{C} \alpha$ and ${ }^{13} \mathrm{C} \beta$ chemical shift values are sensitive for secondary structure, they are shown in Fig. 3 as differences to the random coil values (taken from literature ${ }^{58}$ ) for $\mathrm{pGlu}_{3} \mathrm{~A} \beta(3-40)$ and $\mathrm{pGlu}_{11} \mathrm{~A} \beta(11-40)$ oligomers. For comparison, also the chemical shift data for the mature fibrils of the respective peptides ${ }^{44,45}$ are plotted into the same diagrams. According to the chemical shift values, the differences between oligomers and mature fibrils with regard to their secondary structure are rather small for both pyroglutamate modified peptides. The two $\beta$-strands in the region of $\mathrm{Glu}_{11}-\mathrm{Glu}_{22}$ and $\mathrm{Gly}_{29}-\mathrm{Gly}_{38}$, which are typical for $\mathrm{A} \beta(1-40)$, are already formed in the oligomeric state. Some small deviations between the oligomers and the mature fibrils can be found in the vicinity of the pyroglutamate modification: for $\mathrm{pGlu}_{11} \mathrm{~A} \beta(11-40)$ oligomers only for the direct neighbor in the amino acid sequence $\mathrm{Val}_{12}$, for $\mathrm{pGlu}_{3}-\mathrm{A} \beta(3-40)$ oligomers in addition to $\mathrm{Phe}_{4}$ also for $\mathrm{Asp}_{7}$. Differences in the chemical shift values can also be observed for $\mathrm{Phe}_{19}$. Here, some unusual values were reported for the mature fibrils of $\mathrm{pGlu}_{3}-\mathrm{A} \beta(3-40)$ (two signals) ${ }^{44}$ and $\mathrm{pGlu}_{11} \mathrm{~A} \beta(11-40),{ }^{45}$ therefore, here the values for the oligomers of these peptides match with those for wild type $A \beta(1-40)$ fibrils. ${ }^{59}$

For a further comparison between oligomers of this study and the respective mature fibrils Fig. 5(A and B) exhibit the correlation plots for the $\mathrm{C} \alpha-\mathrm{C} \beta$ chemical shift difference (which is very sensitive to changes in the secondary structure and independent of chemical shift referencing) between pyroglutamate modified oligomers and mature fibrils. For both variants, a very good correlation is obtained.

To compare the oligomers of the pyroglutamyl-modified peptides with oligomers of WT-A $\beta(1-40)$, Fig. 4 shows the ${ }^{13} \mathrm{C} \alpha$ and ${ }^{13} \mathrm{C} \beta$ chemical shifts values of $\mathrm{pGlu} \mathrm{u}_{3}-\mathrm{A} \beta(3-40)$ and $\mathrm{pGlu}_{11} \mathrm{~A} \beta(11-40)$ oligomers together with literature data from WT-A $\beta(1-40)$ oligomers, ${ }^{20}$ which were prepared according the same procedure used in this study, in a similar way as above. A comparison is somewhat hampered by the fact that the

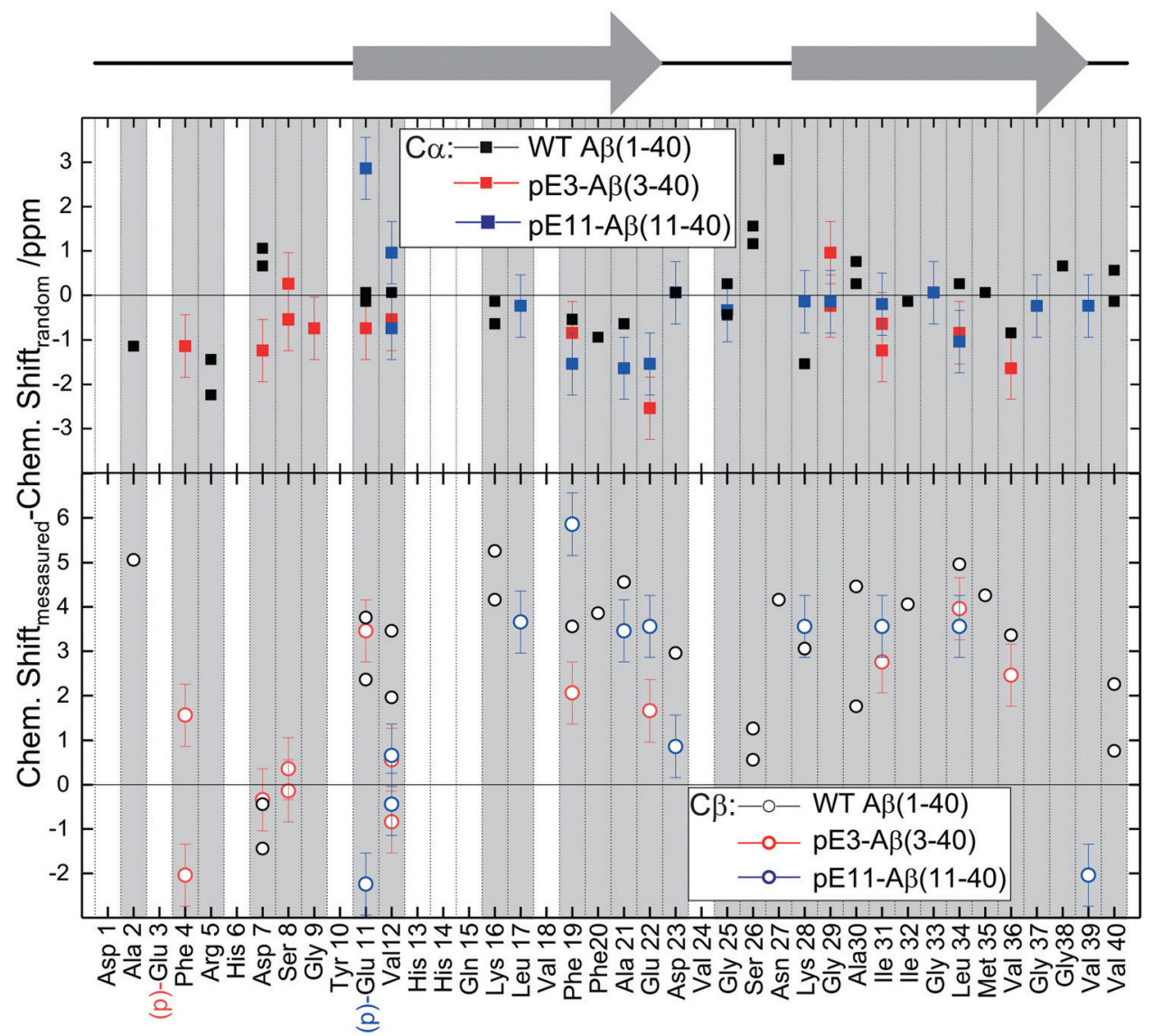

Fig. 4 Comparison of the secondary ${ }^{13} C$ MAS NMR chemical shifts for $C \alpha$ (top) and $C \beta$ (bottom) of the oligomers of $p G l u_{3}-A \beta(3-40)$ (red) and $p G l u_{11}{ }^{-}$ $A \beta(11-40)$ (blue) and WT-A $\beta(1-40)$ (black, data taken from literature ${ }^{20}$ ). Data are plotted as the difference of a measured chemical shifts to random coil chemical shifts for each residue. ${ }^{58}$ For the pGlu residues the random coil values of Glu were used as no reference values for pGlu are available. The arrows above the plots indicate $\beta$-strand secondary structure, the gray area in the plots indicate the ${ }^{13} \mathrm{C}$ labeled amino acids in a least one of the studies. 
labeling pattern of the studied peptides investigated is different. Nevertheless, overall, the pattern for all three oligomers is quite similar and the secondary structure elements are present for all three samples. Small differences in these values are only observed for amino acids close to the pyroglutamate modification at the N-terminus. Only for $\mathrm{Phe}_{19}$, some additional differences in the chemical shift values for $\mathrm{C} \beta$ are observed. For additional comparison, Fig. 5C and D exhibits the correlation plots for the $\mathrm{C} \alpha-\mathrm{C} \beta$ chemical shift difference between the here investigated oligomers of $\mathrm{pGlu}_{3}-\mathrm{A} \beta(3-40)$ and $\mathrm{pGlu}_{11} \mathrm{~A} \beta(11-40)$ and the oligomers of WT-A $\beta(1-40) .{ }^{20}$ Again, at least for the amino acid labeled in both studies a very good correlation is archived.

To obtain insights into the three-dimensional structural arrangement of the two $\beta$-strands of $A \beta(1-40)$, the wellstudied hydrophobic tertiary contact between the side chains of $\mathrm{Phe}_{19}$ and $\mathrm{Leu}_{34},{ }^{7,8,47,60}$ which is already formed during early stages of the fibrillation, ${ }^{16,19,20,24,53,61,62}$ was addressed. Using NMR REDOR measurements, the ${ }^{15} \mathrm{~N}-{ }^{13} \mathrm{CO}$ distance between these two residues was determined to about $4 \AA$ for oligomers and about $7 \AA$ for mature fibrils. ${ }^{53}$ Also, in other structural models for oligomers and mature fibrils, similar distances between the side chains of these residues can be found. ${ }^{7,9,18,60}$

The formation of this molecular contact was investigated using ${ }^{13} \mathrm{C}-{ }^{13} \mathrm{C}$ DARR experiments with a long mixing time of $500 \mathrm{~ms}$. The respective NMR spectra for oligomers for both modified peptides are shown in ESI, $\dagger$ Fig. S4. In both cases, a clear cross peak, indicating magnetization exchange between the aromatic ring of $\mathrm{Phe}_{19}$ and the side chain of $\mathrm{Leu}_{34}$, is observed. Therefore, also in the oligomers of the pyroglutamated variants of $A \beta(1-40)$ both residues are close in space and the contact between these amino acids seems already established, which means that the two $\beta$-strands are already in an arrangement close to each other. This again indicates a structural similarity between the oligomers of pGlu $\mathrm{u}_{3}-\mathrm{A} \beta(3-40)$ and $\mathrm{pGlu}_{11} \mathrm{~A} \beta(11-40)$ and the known structures of WT-A $\beta(1-40)$.

One interesting molecular detail which was found for $A \beta$ oligomers and also protofibrils on the one hand and mature fibrils on the other is the structural arrangement of the edges of the two $\beta$-strands. Previous work has shown that alterations in this region results in structural models, where the respective
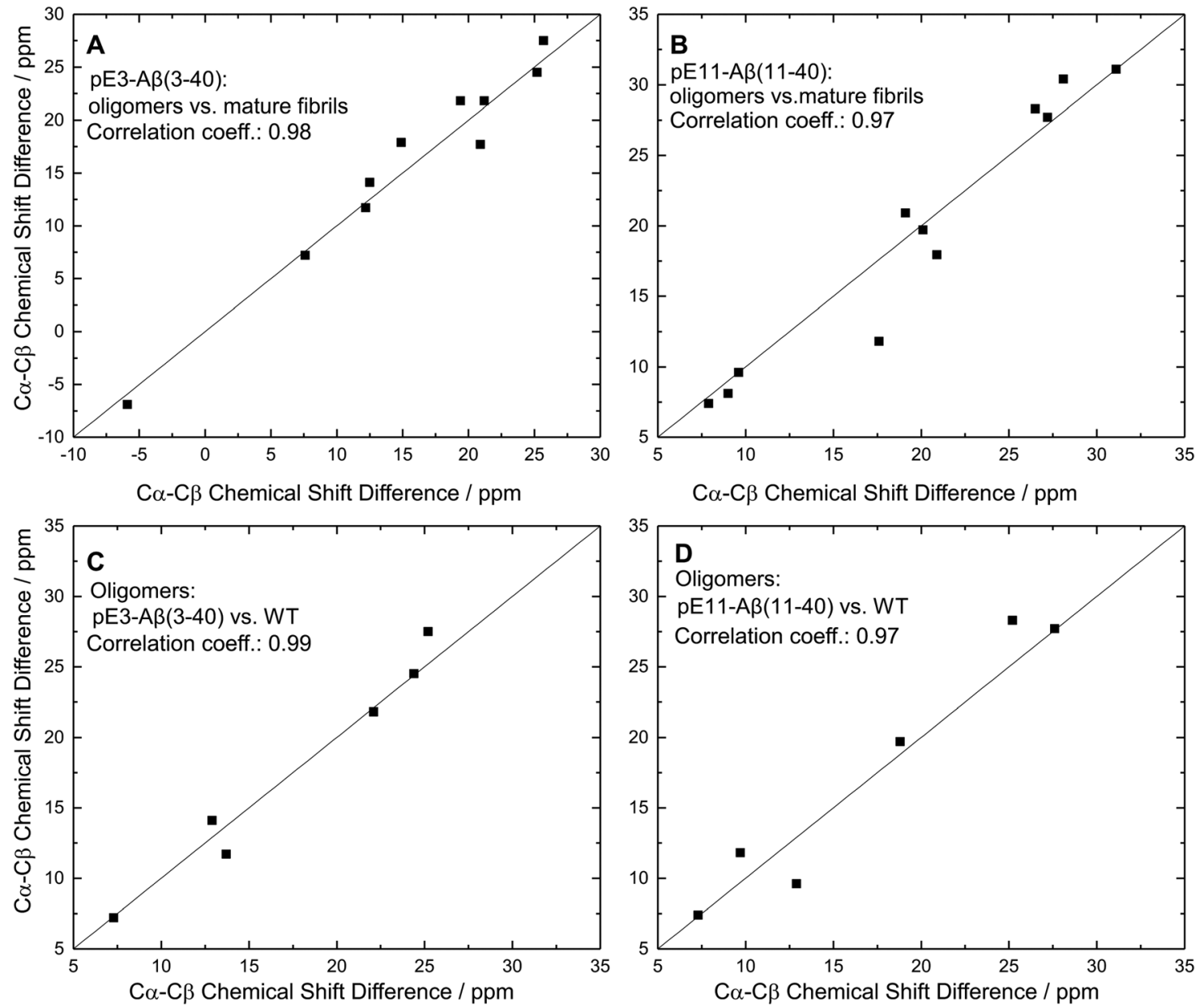

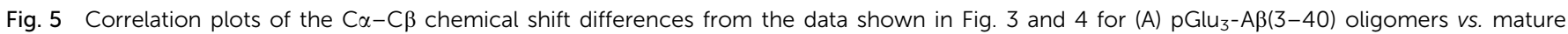

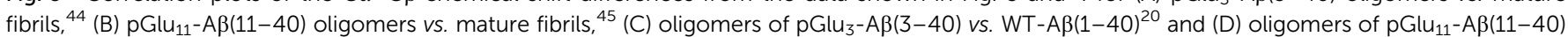

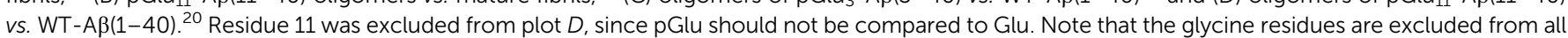
plots since $C \alpha-C \beta$ chemical shift differences are shown. The Pearson correlation coefficient is given on each plot. 
hydrogen bonds between $\beta$-strands are intramolecular for oligomers instead of the known intermolecular organization for mature fibrils. ${ }^{24,51}$ From these findings, a rearrangement of the hydrogen bond pattern during the fibrillation process was suggested. This structurally interesting region can be addressed by studying the molecular contact between the residues $\mathrm{Glu}_{22}$ and $\mathrm{Ile}_{31}$, since the side chains of these residues point towards each other in antiparallel $\beta$-sheets connected by intramolecular hydrogen bonds for oligomers and away from each other in the parallel $\beta$-sheets with intermolecular hydrogen bonds of mature fibrils. Consequently, this molecular contact was found in structural studies of $A \beta$ oligomers and protofibrils ${ }^{18,63}$ but not in mature fibrils of WT-A $\beta(1-40)^{63}$ or both variants of pyroglutamated $A \beta .^{44,45}$ For the oligomers of both pyroglutamated variants of $A \beta(1-40)$ of the current study, the cross peak between $\mathrm{Glu}_{22}$ and $\mathrm{Ile}_{31}$ could not be observed in the respective ${ }^{13} \mathrm{C}-{ }^{13} \mathrm{C}$ DARR NMR spectra. Also, the contact between Gly ${ }_{25}$ and $\mathrm{Ile}_{31}$, which was only observed for mature fibrils of pGlu ${ }_{11}-\mathrm{A} \beta(11-40)^{45}$ could not be observed. So far one can only speculate about the reason for this: too weak signal intensities of the respective cross peaks due to the small amount of sample after the oligomer preparation in this study is probable. Also possible is an influence of the affibodies/antibodies, which were used to stabilize the intermediate states during $A \beta$ fibrillation in the studies were the contact $\mathrm{Glu}_{22}$ and $\mathrm{Ile}_{31}$ was observed. ${ }^{18,63}$

\section{Conclusions}

The procedure for $A \beta$ oligomer preparation used here leads to an ensemble of small oligomeric structures, which is characterized by structural polymorphism in the samples as well as alterations in the molecular dynamics inferred from the observation of increased NMR line widths. The interpretation of such complex samples in terms of a simple molecular model of $\mathrm{A} \beta$ oligomers is quite complex. Nevertheless, overall one has to conclude that oligomers of $\mathrm{pGlu}_{3} \mathrm{~A} \beta(3-40)$ and $\mathrm{pGlu}_{11^{-}}$ $A \beta(11-40)$ exhibit a close similarity to mature fibrils of the same peptides with regard to secondary structure. Also, known tertiary contacts between the two $\beta$-strands were observed to be similar. The structural elements (unstructured N-terminus, two $\beta$-strands connected by a short loop) of $A \beta(1-40)$ in fibrils seems already well formed in these oligomers. At least for the investigated residues, a high similarity to oligomeric species of WT-A $\beta(1-40)$ has been found. ${ }^{15,20}$ The small differences in the $\mathrm{N}$-terminal region can be related to the pyroglutamate modification, but may also point to a possible role of the N-terminus during the fibrillation process. Also for WT-A $\beta(1-40)$ oligomers, differences in the NMR chemical shift values compared to mature fibrils were observed in this region of the molecule, ${ }^{20}$ and additional differences in the dynamics of $\mathrm{N}$-terminal residues in different fibrillation stages of WT-A $\beta(1-40)$ argue in this direction. ${ }^{59,64}$ Furthermore, also for a phosphorylation at $\mathrm{Ser}_{8}$ structural changes in the $\mathrm{N}$-terminus that influence the maturation of the fibrils were reported. ${ }^{31}$ Overall, modifications in the flexible $\mathrm{N}$-terminal region seem to have only minimal effects on the secondary structure of the $A \beta$ oligomers, especially the parts in $\beta$-strand conformation are not influenced. However, the properties of the disordered $\mathrm{N}$-terminal are crucial in determining the toxicity. It was recently shown that an interaction between the $\mathrm{N}$-terminus and an intracellular component is important for toxicity. ${ }^{65}$ This manuscript reinforces that notion.

\section{Conflicts of interest}

There are no conflicts of interest to declare.

\section{Acknowledgements}

We thank Dr Yuning Hong (La Trobe University) for her generous gift of the TPE-TPP dye. SM acknowledges support of the Department of Atomic Energy, Government of India, provided under project no. RTI4003. The study was supported by the Deutsche Forschungsgemeinschaft, DFG, project number 189853844-SFB TRR 102 (A06).

\section{References}

1 D. M. Walsh and D. J. Selkoe, J. Neurochem., 2007, 101, 1172-1184.

2 I. Benilova, E. Karran and S. B. De, Nat. Neurosci., 2012, 15, 349-357.

3 F. Bemporad and F. Chiti, Chem. Biol., 2012, 19, 315-327.

4 M. Diociaiuti, G. Macchia, S. Paradisi, C. Frank, S. Camerini, P. Chistolini, M. C. Gaudiano, T. C. Petrucci and F. MalchiodiAlbedi, Biochim. Biophys. Acta, 2014, 1842, 1622-1629.

5 J. Bieschke, M. Herbst, T. Wiglenda, R. P. Friedrich, A. Boeddrich, F. Schiele, D. Kleckers, J. M. Lopez Del Amo, B. A. Gruning, Q. Wang, M. R. Schmidt, R. Lurz, R. Anwyl, S. Schnoegl, M. Fandrich, R. F. Frank, B. Reif, S. Gunther, D. M. Walsh and E. E. Wanker, Nat. Chem. Biol., 2012, 8, 93-101.

6 A. T. Petkova, Y. Ishii, J. J. Balbach, O. N. Antzutkin, R. D. Leapman, F. Delaglio and R. Tycko, Proc. Natl. Acad. Sci. U. S. A., 2002, 99, 16742-16747.

7 A. K. Paravastu, R. D. Leapman, W. M. Yau and R. Tycko, Proc. Natl. Acad. Sci. U. S. A., 2008, 105, 18349-18354.

8 I. Bertini, L. Gonnelli, C. Luchinat, J. Mao and A. Nesi, J. Am. Chem. Soc., 2011, 133, 16013-16022.

9 J. X. Lu, W. Qiang, W. M. Yau, C. D. Schwieters, S. C. Meredith and R. Tycko, Cell, 2013, 154, 1257-1268.

10 M. A. Walti, F. Ravotti, H. Arai, C. G. Glabe, J. S. Wall, A. Bockmann, P. Guntert, B. H. Meier and R. Riek, Proc. Natl. Acad. Sci. U. S. A., 2016, 113, E4976-E4984.

11 M. T. Colvin, R. Silvers, Q. Z. Ni, T. V. Can, I. Sergeyev, M. Rosay, K. J. Donovan, B. Michael, J. Wall, S. Linse and R. G. Griffin, J. Am. Chem. Soc., 2016, 138, 9663-9674.

12 Y. Xiao, B. Ma, D. McElheny, S. Parthasarathy, F. Long, M. Hoshi, R. Nussinov and Y. Ishii, Nat. Struct. Mol. Biol., 2015, 22, 499-505. 
13 L. Gremer, D. Scholzel, C. Schenk, E. Reinartz, J. Labahn, R. B. G. Ravelli, M. Tusche, C. Lopez-Iglesias, W. Hoyer, H. Heise, D. Willbold and G. F. Schroder, Science, 2017, 358, 116-119.

14 M. Kollmer, W. Close, L. Funk, J. Rasmussen, A. Bsoul, A. Schierhorn, M. Schmidt, C. J. Sigurdson, M. Jucker and M. Fandrich, Nat. Commun., 2019, 10, 4760.

15 S. Chimon and Y. Ishii, J. Am. Chem. Soc., 2005, 127, 13472-13473.

16 M. Ahmed, J. Davis, D. Aucoin, T. Sato, S. Ahuja, S. Aimoto, J. I. Elliott, W. E. Van Nostrand and S. O. Smith, Nat. Struct. Mol. Biol., 2010, 17, 561-567.

17 S. A. Kotler, J. R. Brender, S. Vivekanandan, Y. Suzuki, K. Yamamoto, M. Monette, J. Krishnamoorthy, P. Walsh, M. Cauble, M. M. Holl, E. N. Marsh and A. Ramamoorthy, Sci. Rep., 2015, 5, 11811.

18 W. Hoyer, C. Gronwall, A. Jonsson, S. Stahl and T. Härd, Proc. Natl. Acad. Sci. U. S. A., 2008, 105, 5099-5104.

19 H. A. Scheidt, I. Morgado, S. Rothemund, D. Huster and M. Fändrich, Angew. Chem., Int. Ed., 2011, 50, 2837-2840.

20 B. Sarkar, V. S. Mithu, B. Chandra, A. Mandal, M. Chandrakesan, D. Bhowmik, P. K. Madhu and S. Maiti, Angew. Chem., Int. Ed., 2014, 53, 6888-6892.

21 S. Chimon, M. A. Shaibat, C. R. Jones, D. C. Calero, B. Aizezi and Y. Ishii, Nat. Struct. Mol. Biol., 2007, 14, 1157-1164.

22 J. C. Stroud, C. Liu, P. K. Teng and D. Eisenberg, Proc. Natl. Acad. Sci. U. S. A., 2012, 109, 7717-7722.

23 E. Cerf, R. Sarroukh, S. Tamamizu-Kato, L. Breydo, S. Derclaye, Y. F. Dufrene, V. Narayanaswami, E. Goormaghtigh, J. M. Ruysschaert and V. Raussens, Biochem. J., 2009, 421, 415-423.

24 A. Sandberg, L. M. Luheshi, S. Sollvander, B. T. Pereira de, B. Macao, T. P. Knowles, H. Biverstal, C. Lendel, F. EkholmPetterson, A. Dubnovitsky, L. Lannfelt, C. M. Dobson and T. Härd, Proc. Natl. Acad. Sci. U. S. A., 2010, 107, 15595-15600.

25 Y. Gao, C. Guo, J. O. Watzlawik, P. S. Randolph, E. J. Lee, D. Huang, S. M. Stagg, H. X. Zhou, T. L. Rosenberry and A. K. Paravastu, J. Mol. Biol., 2020, 2836, 30354-30355.

26 H. Steiner, A. Fukumori, S. Tagami and M. Okochi, Cell Stress., 2018, 2, 292-310.

27 M. P. Kummer and M. T. Heneka, Alzheimer's Res. Ther., 2014, 6, 28.

28 E. Cabrera, P. Mathews, E. Mezhericher, T. G. Beach, J. Deng, T. A. Neubert, A. Rostagno and J. Ghiso, Biochim. Biophys. Acta, 2018, 1684, 208-225.

29 S. Jawhar, O. Wirths and T. A. Bayer, J. Biol. Chem., 2011, 286, 38825-38832.

30 Y. K. Al-Hilaly, T. L. Williams, M. Stewart-Parker, L. Ford, E. Skaria, M. Cole, W. G. Bucher, K. L. Morris, A. A. Sada, J. R. Thorpe and L. C. Serpell, Acta Neuropathol. Commun., 2013, 1, 83.

31 N. Rezaei-Ghaleh, S. Kumar, J. Walter and M. Zweckstetter, J. Biol. Chem., 2016, 291, 16059-16067.

32 A. P. Gunn, C. L. Masters and R. A. Cherny, Int. J. Biochem. Cell Biol., 2010, 42, 1915-1918.

33 A. P. Gunn, B. X. Wong, T. Johanssen, J. C. Griffith, C. L. Masters, A. I. Bush, K. J. Barnham, J. A. Duce and R. A. Cherny, J. Biol. Chem., 2016, 291, 6134-6145.
34 D. Schlenzig, R. Ronicke, H. Cynis, H. H. Ludwig, E. Scheel, K. Reymann, T. Saido, G. Hause, S. Schilling and H. U. Demuth, J. Neurochem., 2012, 121, 774-784.

35 S. Schilling, U. Zeitschel, T. Hoffmann, U. Heiser, M. Francke, A. Kehlen, M. Holzer, B. Hutter-Paier, M. Prokesch, M. Windisch, W. Jagla, D. Schlenzig, C. Lindner, T. Rudolph, G. Reuter, H. Cynis, D. Montag, H. U. Demuth and S. Rossner, Nat. Med., 2008, 14, 1106-1111.

36 M. Wulff, M. Baumann, A. Thummler, J. K. Yadav, L. Heinrich, U. Knupfer, D. Schlenzig, A. Schierhorn, J. U. Rahfeld, U. Horn, J. Balbach, H. U. Demuth and M. Fandrich, Angew. Chem., Int. Ed., 2016, 55, 5081-5084.

$37 \mathrm{~W}$. He and C. J. Barrow, Biochemistry, 1999, 38, 10871-10877.

38 C. Dammers, L. Gremer, K. Reiss, A. N. Klein, P. Neudecker, R. Hartmann, N. Sun, H. U. Demuth, M. Schwarten and D. Willbold, PLoS One, 2015, 10, e0143647.

39 M. Morawski, S. Schilling, M. Kreuzberger, A. Waniek, C. Jager, B. Koch, H. Cynis, A. Kehlen, T. Arendt, M. HartlageRubsamen, H. U. Demuth and S. Rossner, J. Alzheimer's. Dis., 2014, 39, 385-400.

40 J. M. Nussbaum, S. Schilling, H. Cynis, A. Silva, E. Swanson, T. Wangsanut, K. Tayler, B. Wiltgen, A. Hatami, R. Ronicke, K. Reymann, B. Hutter-Paier, A. Alexandru, W. Jagla, S. Graubner, C. G. Glabe, H. U. Demuth and G. S. Bloom, Nature, 2012, 485, 651-655.

41 T. C. Saido, W. Yamao-Harigaya, T. Iwatsubo and S. Kawashima, Neurosci. Lett., 1996, 215, 173-176.

42 C. Russo, T. C. Saido, L. M. DeBusk, M. Tabaton, P. Gambetti and J. K. Teller, FEBS Lett., 1997, 409, 411-416.

43 C. P. Sullivan, E. A. Berg, R. Elliott-Bryant, J. B. Fishman, A. C. McKee, P. J. Morin, M. A. Shia and R. E. Fine, Neurosci. Lett., 2011, 505, 109-112.

44 H. A. Scheidt, J. Adler, M. Krueger and D. Huster, Sci. Rep., 2016, 6, 33531.

45 H. A. Scheidt, J. Adler, U. Zeitschel, C. Hofling, A. Korn, M. Krueger, S. Rossner and D. Huster, Chemistry, 2017, 23, 15834-15838.

46 A. K. Das, A. Rawat, D. Bhowmik, R. Pandit, D. Huster and S. Maiti, ACS Chem. Neurosci., 2015, 6, 1290-1295.

47 J. Adler, H. A. Scheidt, M. Kruger, L. Thomas and D. Huster, Phys. Chem. Chem. Phys., 2014, 16, 7461-7471.

48 F. Hoffmann, J. Adler, B. Chandra, K. R. Mote, G. BekciogluNeff, D. Sebastiani and D. Huster, J. Phys. Chem. Lett., 2017, 8, 4740-4745.

49 A. Korn, S. McLennan, J. Adler, M. Krueger, D. Surendran, S. Maiti and D. Huster, ACS Chem. Neurosci., 2018, 9, 790-799.

50 A. K. Schutz, T. Vagt, M. Huber, O. Y. Ovchinnikova, R. Cadalbert, J. Wall, P. Guntert, A. Bockmann, R. Glockshuber and B. H. Meier, Angew. Chem., Int. Ed., 2015, 54, 331-335.

51 T. Härd, FEBS J., 2011, 278, 3884-3892.

52 A. Das, A. Gupta, Y. Hong, J. A. Carver and S. Maiti, Biochemistry, 2020, 59, 1813-1822. 
53 B. Chandra, D. Bhowmik, B. K. Maity, K. R. Mote, D. Dhara, R. Venkatramani, S. Maiti and P. K. Madhu, Biophys. J., 2017, 113, 805-816.

54 T. Gopinath and G. Veglia, Angew. Chem., Int. Ed., 2012, 51, 2731-2735.

55 S. T. Kumar, J. Leppert, P. Bellstedt, C. Wiedemann, M. Fandrich and M. Gorlach, J. Mol. Biol., 2016, 428, 268-273.

56 A. K. Paravastu, A. T. Petkova and R. Tycko, Biophys. J., 2006, 90, 4618-4629.

57 A. T. Petkova, R. D. Leapman, Z. Guo, W. M. Yau, M. P. Mattson and R. Tycko, Science, 2005, 307, 262-265.

58 D. S. Wishart and B. D. Sykes, Methods Enzymol., 1994, 239, 363-392.

59 H. A. Scheidt, I. Morgado, S. Rothemund and D. Huster, J. Biol. Chem., 2012, 287, 2017-2021.
60 T. Lührs, C. Ritter, M. Adrian, D. Riek-Loher, B. Bohrmann, H. Dobeli, D. Schubert and R. Riek, Proc. Natl. Acad. Sci. U. S. A., 2005, 102, 17342-17347.

61 W. M. Tay, D. Huang, T. L. Rosenberry and A. K. Paravastu, J. Mol. Biol., 2013, 425, 2494-2508.

62 A. Potapov, W. M. Yau, R. Ghirlando, K. R. Thurber and R. Tycko, J. Am. Chem. Soc., 2015, 137, 8294-8307.

63 H. A. Scheidt, I. Morgado and D. Huster, J. Biol. Chem., 2012, 287, 22822-22826.

64 C. Lendel, T. Sparrman, M. Mayzel, C. E. Andersson, G. Karlsson and T. Härd, ChemistrySelect, 2016, 1, 5850-5853.

65 B. K. Maity, A. K. Das, S. Dey, U. K. Moorthi, A. Kaur, A. Dey, D. Surendran, R. Pandit, M. Kallianpur, B. Chandra, M. Chandrakesan, S. Arumugam and S. Maiti, ACS Chem. Neurosci., 2019, 10, 2498-2509. 